\title{
Pharmacist intervention in home care program for diabetes patients*
}

\author{
Syed Wasif Gillani ${ }^{1 \#}$, Syed Azhar Syed Sulaiman ${ }^{1}$, Mirza Baig ${ }^{2}$, Yelly Oktavia Sari ${ }^{3,4}$, \\ Siti Maisharah Sheikh Ghadzi ${ }^{5}$, Sabariah Noor Haroon ${ }^{5}$, Nur Hafzan Md Hanafiah ${ }^{5}$
}

${ }^{1}$ School of Pharmaceutical Sciences, Universiti Sains Malaysia, Gelugor, Malaysia;

${ }^{\#}$ Corresponding Author: wasifgillani@gmail.com

${ }^{2}$ Department of Clinical Pharmacy, Aimst University, Bedong, Malaysia

${ }^{3}$ Faculty of Pharmacy, Andalas University, Padang, Indonesia

${ }^{4}$ Discipline of Clinical Pharmacy, School of Pharmaceutical Sciences, Universiti Sains Malaysia, Minden, Malaysia

${ }^{5}$ School of Pharmaceutical Sciences, Universiti Sains Malaysia, Kubang Kerian, Malaysia

Received 11 May 2012; revised 15 June 2012; accepted 28 June 2012

\section{ABSTRACT}

Majority of research reports identified moderate reduction in glycated haemoglobin with education interventions regardless of age group. Our study objective was to evaluate the pharmacist interventions in providing patient home care. A 24-week longitudinal quasi-experimental-pretest/post-test study design was used to assess the effectiveness of a diabetes education program to enhance self-care practices. A doubleblinded randomized study design was considered but was not feasible as the investigator was responsible for implementing the intervention and collecting data on outcomes. Since this was a longitudinal study a $25 \%$ attrition rate was included in the calculation of sample size. Hence the sample size for the proposed study was 106 subjects with 53 subjects in each group. All analyses were done using SPSS version $18^{\circledR}$. The level of significance was set at 0.05 . The Research Ethics Committee of hospital and the Malaysian Medical Research and Ethics Committee approved the study. Of the 109 subject who met the study-entry criteria, 3 subjects declined to participate due to lack of time and interest. There was no significant relationship between the demographic and clinical characteristic of participants who completed the study. No significant relationship between the intervention and control groups who completed the study in demographic, clinical and psychosocial contexts. Of the 47 subjects from the intervention group who reported adherent to their daily medication intake after the education intervention, 51 subjects $(31.9 \%)$ reported taking their

${ }^{*}$ All these authors contributed equally to this work. Conflict of interest: no. medication at the wrong time. The recommended times for oral anti-hyperglycemic medication (OAM) are: sulphonylureas 30 minutes before food, acarbose with food, metformin with or within $\mathbf{3 0}$ minutes after food. This research has shown a brief structured education program that incorporated behavior science specifically selfefficacy was effective in enhancing self-care practices (SMBG and medication adherence) and improving glycaemic control in the intervention group.

Keywords: Diabetes Mellitus; Interventional Study; Longitudinal Study; Pharmacist Services

\section{INTRODUCTION}

It reported that the greatest effect was knowledge improvement with small effects on self-care behavior, metabolic control and psychological well-being [1]. The same author replicated these findings with 35 additional studies which focused on the effects of different educational strategies on patient outcomes reported similar results [1-3]. Recent systemic reviews that examined the effectiveness of self-management training of type 2 diabetes based on randomized controlled trials also found significant findings on knowledge improvement regardless of the educational strategies used [4-6]. With regular reinforcement, knowledge level can be sustained for 24 months $[3,6]$.

Patient education appears more effective in younger patients particularly knowledge outcome [7]. No other demographic variable is reposted in relation to knowledge improvement in the meta-analysis. Whereas health literacy literature indicates older subjects, those with less education, minority ethnic groups and do not speak English are factors associated with low health literacy. These 
subjects often benefit less from education interventions [8-10]. The positive effects of knowledge outcomes via diabetes education must be interpreted within the methodological limitation like possible contamination due to infeasibility of participant blinding, lack of uniform measures of knowledge and the validity of the tools use [6,8,11-13]. Hence the next question is to investigate whether the beneficial effects of education go beyond knowledge.

Majority of research reports identified moderate reduction in glycated haemoglobin with education interventions regardless of age group [8,14-16]. The glycated haemoglobin levels improve between one to six months post-intervention and the level frequently returned to baseline after six months $[3,6,11]$. Studies with follow up periods longer than one year showed mixed effects on glycaemic control [6,17-21]. Since most positive studies were short-term studies, there is concern about the lack of long-term glycaemic improvement.

Education methodology appears to influence glycaemic control. Compared to didactic interventions, patient collaborative interventions produce more favorable results particularly if the interventions are repetitive and ongoing $[15,22-24]$. In a meta-analysis, face to face delivery, cognitive reframing teaching and studies that included exercise content explained $44 \%$ of the variance in glycaemic control [25]. A meta-analysis reported that if require 23.6 hours of education to reduce $1 \%$ of HbAlc [26].

Some researchers have reported improvement of glycaemic control in both the control and study groups. In these studies, the education interventions were usually unblended [6]. In addition, lack of standardized measurements of glycated haemoglobin such as shorter than 12 week duration might not have documented the full effect of the interventions [6,27].

Our study objective aimed on three clinical hypothesis; There will be no difference in medication adherence self-care practices between adults with poorly controlled diabetes who receive a structured self-efficacy education compared to those who received standard education, there will be no difference in SMBG self-care practices between adults with poorly controlled diabetes who receive a structured self-efficacy education compared to those who receive standard education, and there will be no difference in glycaemic control measured by glycated haemoglobin $(\mathrm{HbAlc})$ between adults with poorly controlled diabetes who receive a structured self-efficacy education compared to those who receive standard education.

\section{METHDOLOGY}

\subsection{Research Design}

The purpose of this study was to examine the effect of an intervention. For logistical reason, this study was necessarily a small one and had to be completed within the study period. A 24-week longitudinal quasi-experimental-pre-test/post-test study design was used to assess the effectiveness of a diabetes education program to enhance self-care practices [28]. A double-blinded randomized study design was considered but was not feasible as the investigator was responsible for implementing the intervention and collecting data on outcomes [28,29].

\subsection{Theoretical Framework}

Findings from literature reviews have shown the importance of incorporating behavioral theories in Diabetes Self-management Education interventions because they provide an understanding of the cognitive and psychosocial processes that influence health decision-making and behavior. Self-efficacy has been shown to act as the mediating link between cognitive preparation (knowledge and skill) and actual task engagement [30-32]. Furthermore, when comparing self-efficacy to other psychosocial interventions, self-efficacy emerged as better predictor of self-care adherence to diet, exercise and blood glucose monitoring. It shared $4 \%$ to $26 \%$ of variance of self-care behavior when compared to Health Belief Model, outcome expectancies, autonomous self-regulation and social support in both Type 1 and Type 2 diabetes [30-32]. Hence self-efficacy in-home practice was the choice of theoretical framework for this study.

\subsection{Subjects}

\subsubsection{Inclusion Criteria}

Subjects were included if they:

- Were non-pregnant adults $>18$ years of age regardless of gender or ethnicity;

- Had diabetes for more than a year;

- Spoke and understood Bahasa Malaysia, English, Mandarin or Chinese dialects (Cantonese, Hokkien or Teow-chew) as these were the languages used during the pre-and post-assessments and education interventions;

- Had a medical record showing poor diabetes control*; *Poor diabetes control in this study was defined as HbA1c of more than $7 \%$ for two reasons. First the currently global recommended glycaemic target measured by $\mathrm{HbA} 1 \mathrm{c}$ is between $\leq 6.5 \%$ to $\leq 7 \%$. Second, empirical studies reported that $\mathrm{HbA1c}$ of more than $7 \%$ is associated with increased micro-vascular complications [3336].

\subsubsection{Exclusion Criteria}

Subjects were excluded from the study if they:

- Were above 18 years of age but unable to answer the questionnaire independently due to mental illness, se- 
nility, other co-morbidities, unstable medical condition such as in-patients;

- Had hearing impairment as they might have had problems with telephone follow-ups for education and data collection;

- Had vision impairment as they might not be able to assess the portion size of their carbohydrate intake or prescribed medication;

- Were pregnant women with diabetes or diagnosed with gestational diabetes due to the different criteria on standard of control.

\subsubsection{Sample Size}

The required sample size was calculated with a power analysis using the procedure provided by Polit and Hungler [37]. Self-care practice was the primary outcome. The power was set at 0.7 with an alpha of 0.05 . The investigator was unable to calculate the effect size using previous studies as there are no previous studies that measure the four self-care practices together. Hence the convention developed by Cohen (1988 cited in Polit and Hungler) was used (p492) [37]. Based on this, the value of effect size in a two-group test of mean difference was estimated at $0.20-0.49$ for small effect, $0.50-0.79$ for medium effect and 0.80 for large effect. To test for a significant difference between the two groups, a medium effect size of Gamma 0.5 was arbitrarily adopted, requiring a sample size of 42 in each group or a total of 84 . Since this was a longitudinal study a $25 \%$ attrition rate was included in the calculation of sample size. Hence the sample size for the proposed study was 106 subjects with 53 subjects in each group.

\subsection{Setting}

One hundred and sixty subjects with poor diabetes control were recruited from the general medical outpatients clinics of general hospital in the state of Penang. A general hospital was defined as the main government hospital in the state offering tertiary care. Subjects were not recruited from the private clinics and hospitals for reasons of possible demographic and psychosocial differences which could affect the intervention outcomes. Controls were intervened in their respective homes while controls were observed in the usual appointments at out-patient department of the hospital.

\subsection{Research Tools}

Three research instruments were used in this study: measurement of glycated haemoglobin, an assessment tools and an education program.

Glycated Haemoglobin (HbA1c) was computed by using reference analogue of serum glucose values analysed by using Johnson-Johnson One-Touch Ultra 2 Me- ter. Self-monitoring practices in home was performed by the patient and later researcher computed HbAlc on weekly basis.

\subsection{Medication Intake Practices}

Assessment of medication adherence included the subjects' reported medication intake on dosage and frequency which was compared with the physicians' prescriptions for concordance at the baseline. Compared to DSA questionnaire, 4 items were used to assess adherence to timing of daily medication adherence in the preceding week with a 8 -point scale from " 0 " to "7" day, 4 items were used to assess the insulin users' injection skills and 3 items were added to assess for correct medication timing in relation to food intake. Percentage of medication adherence was calculated based on the data from subjects description of medication intake on dosage and frequency during the preceding 7 days using the formula in table below [38]. For subjects on combined treatment, the adherence percentage is the mean of oral anti-hyperglycaemia medication (OAM) and insulin adherence rates. Medication adherence rate was defined as consuming $90 \%$ and above of the prescribed medication in the preceding week.

\subsection{Self-Monitoring of Blood Glucose Practice}

At baseline, subjects were asked questions about the recommended weekly frequency of self-monitoring. No score was allocated for recommended frequency. The frequency of SMBG and treatment modification was assessed using a 9-point scale from " 0 " to more than 7 times'. Timing of SMBG was assessed using an 8-point scale from " 0 " to "7". The scoring system was based on the frequency of SMBG and treatment modification done during the preceding week (questions 4, 8 - 10). Although previous studies unanimously recognized the importance of SMBG in diabetes management, there were discrepancies between the recommended frequency and timing of SMBG $[39,40]$. Previous researchers reported less than $25 \%$ of Malaysians with diabetes practiced SMBG $[41,42]$. Hence for the purposes of this study, a minimum of four blood glucose testing in the preceding week was considered as adequate SMBG self-care practice.

\subsection{Pilot Study}

As all patients from the medical out-patient department of the hospital where the investigator was attached had regular $\mathrm{HbA} 1 \mathrm{c}$ testing during their follow-ups, a pilot study was conducted there to assess the reliability, 
content validity and criterion-related validity of the "Revised Diabetes Self-care Activities Questionnaire".

\subsubsection{Subjects}

Subjects were recruited using a systematic sampling approach and every second diabetic subject who met the inclusion criteria was invited to participate until a total of 50 subjects were recruited, which included 48 Type 2 diabetic and 2 Type 1 diabetics.

\subsubsection{Content Validity}

A panel compromising three diabetologists, three diabetes nurse consultants, two dieticians, one pharmacist, two adults with Type 2 diabetes reviewed the questionnaire independently for face and content validity that reflected the daily self-care practices of an individual with diabetes. The content of the questionnaire was also thought to be appropriate with several suggestions given to improve its clarity and precision. An example was re-phasing of "what is the effect of exercise on diabetes control?" to "what is the effect of regular exercise on blood glucose?" It was also suggested to measure the subjects' waist circumference because of the significance to the diagnosis of metabolic syndrome with diabetes [43-45].

\subsubsection{Reliability}

Internal consistency of the Revised Diabetes Self-care Activities Questionnaire was assessed using Cronbach's alpha analysis after the pilot study. The result of the Cronbach's alpha was 0.8 varying from 0.6 to 0.9 .

The low Cronbach alpha value of SMBG could be because it has the least number of items [30] among all sections. According to the formula for Cronbach's alpha calculation, the co-efficient alpha depends on the total number of items and the average inter-item correlation among the items [46,47]. Different timing of SMBG has different significance in diabetes management. $[39,40]$ Hence three further questions to assess the timing of SMBG were added.

\subsection{Ethical Consideration}

The Research Ethics Committee of hospital and the Malaysian Medical Research and Ethics Committee approved the study.

\subsection{Statistical Analysis}

Demographic data was analyzed using descriptive statistics. A 2-tailed t-test was used to analyze any difference between the intervention and control groups and within groups for ratio data such as medication adherence rate. Chi-square was used to analyze the relationship between nominal data such as gender. Multiple re- gressions were performed to predict the variance of different self-care practices after the education with post$\mathrm{HbA1c}$ levels. All analyses were done using SPSS version $18^{\circledR}$. The level of significance was set at 0.05 .

\section{RESULTS}

Of the 109 subject who met the study-entry criteria, 3 subjects declined to participate due to lack of time and interest. One hundred and six subjects were randomized to either control or intervention group with 53 subjects in each group. Thirteen subjects withdrew from the study for reasons of lack of interest $(n=9)$, transferred to either healthcare centre $(n=2)$, severe anaemia and hence were unable to read the post-HbAlc $(n=1)$ and one died. The primary result of this study were based on data from the 93 subject who completed the 24-weeks (6 months) follow-up (intervention $=47$, control $=46$ ).

There was no significant relationship between the demographic and clinical characteristic of participants who completed the study (Table 1).

No significant relationship between the intervention and control groups who completed the study in demographic, clinical and psychosocial contexts. Table 2 presented the detailed information of analysis.

\subsection{Medication Adherence Self-Care}

\subsubsection{Between Groups}

There was no statistically difference in the medication adherence rate between the intervention $(\mathrm{M}=83.21, \mathrm{SD}$ $=17.26)$ and control groups $[\mathrm{M}=84.52, \mathrm{SD}=19.79$; $\mathrm{t}(149)=-1.7, \mathrm{p}=0.06]$ at follow up.

\subsubsection{Within Groups}

Within the intervention group, however, there was a significant difference in medication adherence rate from baseline $(\mathrm{M}=83.21, \mathrm{SD}=17.26)$ to follow-up $[\mathrm{M}=$ $89.50, \mathrm{SD}=17.98, \mathrm{t}(77)=-2.19, \mathrm{p}=0.03]$ with moderate effect size (eta squared $=0.06$ ). This control group did not show any significant difference in medication adherence practices $(\mathrm{M}=84.52, \mathrm{SD}=19.79)$ to follow-up $[\mathrm{M}=84.60, \mathrm{SD}=18.16, \mathrm{t}(72)=-0.04, \mathrm{p}=0.97]$.

\subsection{Factors Influencing Medication Adherence Self-Care}

\subsubsection{Hypoglycaemia Episodes}

During the study, 11 subjects $(23.4 \%)$ from the intervention group reported hypoglycaemic episodes that were confirmed by SMBG results. These subjects adjusted their own insulin dosage to avoid further hypoglycaemic episodes. Unpaired t-test was used to assess whether this influenced medication adherence. Subject with no previous hypoglycaemic episodes had higher medication adherence rate $(\mathrm{M}=91.10, \mathrm{SD}=15.71)$ 
Table 1. Comparison between demographic data of subject who had and had not completed the study at baseline $(n=106)$.

\begin{tabular}{|c|c|c|c|c|}
\hline Subjects & $\begin{array}{c}\text { Participants }=93 \\
\text { mean } \pm(\mathrm{SD}) / \text { percent }\end{array}$ & $\begin{array}{c}\text { Drop-outs }=13 \\
\text { mean } \pm(\text { SD)/percent }\end{array}$ & $X^{2} / t$ & p value \\
\hline Age (years) & $54(10.03)$ & $53(11.43)$ & -0.92 & $0.34^{\neq}$ \\
\hline BMI $\left(\mathbf{k g} / \mathbf{m}^{2}\right)$ & $28.20(5.58)$ & $27.63(6.32)$ & -0.33 & $0.75^{\ddagger}$ \\
\hline Waist circumference (cm) & $94.55(11.49)$ & $94.47(12.8)$ & -0.07 & $0.94^{\neq}$ \\
\hline \multicolumn{5}{|l|}{ Gender } \\
\hline -Male & $60(64.5 \%)$ & $4(30.7 \%)$ & \multirow[t]{2}{*}{0.05} & \multirow[t]{2}{*}{$0.82^{\ddagger}$} \\
\hline -Female & $33(35.5 \%)$ & $9(69.3 \%)$ & & \\
\hline \multicolumn{5}{|l|}{ Education level } \\
\hline -Never & $5(5.4 \%)$ & $1(7.7 \%)$ & \multirow{5}{*}{0.81} & \multirow{5}{*}{$0.93^{\ddagger}$} \\
\hline -Primary & $51(54.8 \%)$ & $7(53.8 \%)$ & & \\
\hline -Secondary & $30(32.3 \%)$ & $4(30.8 \%)$ & & \\
\hline -College & $4(4.3 \%)$ & $1(7.7 \%)$ & & \\
\hline -Tertiary & $3(3.2 \%)$ & $0(0 \%)$ & & \\
\hline HbA1c (\%) & $9.75(1.75)$ & $10.46(1.72)$ & 1.68 & $0.10^{\neq}$ \\
\hline Duration of diabetes (years) & $11.41(8.64)$ & $9.88(8.87)$ & -0.63 & $0.55^{\neq}$ \\
\hline \multicolumn{5}{|l|}{ Diabetes type } \\
\hline -Type 1 & $5(5.4 \%)$ & $2(15.4 \%)$ & & \\
\hline -Type 2 & $88(94.6 \%)$ & $11(84.6 \%)$ & & \\
\hline
\end{tabular}

${ }^{*}$ analysis by t-test; ${ }^{*}$ analysis by Chi-square.

Table 2. Baseline characteristic of subjects who completed the study $(\mathrm{n}=93)$.

\begin{tabular}{|c|c|c|c|c|c|c|}
\hline A. Demographic & \multicolumn{2}{|c|}{$\begin{array}{c}\text { Intervention }(n=47) \\
\text { mean }(S D) / \text { percent }\end{array}$} & \multicolumn{2}{|c|}{$\begin{array}{c}\text { Control }(n=46) \\
\text { mean }(S D) / \text { percent }\end{array}$} & $X^{2} / t$ & p Value \\
\hline Age (years) & 54 & $(9.81)$ & 54 & (10.29) & 0.02 & $0.98^{\neq}$ \\
\hline Gender & & & & & 0.04 & $0.1^{\ddagger}$ \\
\hline Male & 31 & $66.0 \%$ & 29 & $63.0 \%$ & & \\
\hline Female & 16 & $34.0 \%$ & 17 & $37.0 \%$ & & \\
\hline Race & & & & & 4.25 & $0.22^{\ddagger}$ \\
\hline Malay & 28 & $59.6 \%$ & 25 & $54.3 \%$ & & \\
\hline Chinese & 11 & $23.4 \%$ & 12 & $26.1 \%$ & & \\
\hline Indian & 8 & $17.0 \%$ & 9 & $19.6 \%$ & & \\
\hline Education & & & & & -1.25 & $0.11^{\ddagger}$ \\
\hline Never Primary & 3 & $6.4 \%$ & 2 & $4.3 \%$ & & \\
\hline Primary & 25 & $53.2 \%$ & 26 & $56.5 \%$ & & \\
\hline Secondary & 16 & $34.0 \%$ & 14 & $30.4 \%$ & & \\
\hline College & 1 & $2.1 \%$ & 3 & $6.5 \%$ & & \\
\hline
\end{tabular}


Continued

\begin{tabular}{|c|c|c|c|c|c|c|}
\hline Tertiarry & 2 & $4.3 \%$ & 1 & $2.3 \%$ & & \\
\hline Marital status & & & & & 2.56 & $0.21^{\ddagger}$ \\
\hline Single & 3 & $6.4 \%$ & 4 & $8.8 \%$ & & \\
\hline Married & 38 & $80.9 \%$ & 37 & $80.4 \%$ & & \\
\hline Divorced & 1 & $2.1 \%$ & 0 & $0 \%$ & & \\
\hline Separated & 1 & $2.1 \%$ & 2 & $4.3 \%$ & & \\
\hline Windowed & 4 & $8.5 \%$ & 3 & $6.5 \%$ & & \\
\hline \multicolumn{7}{|l|}{ B. Climical Variables } \\
\hline Type of Diabetes & & & & & 1.41 & $0.14^{\ddagger}$ \\
\hline Type 1 & 2 & $4.3 \%$ & 3 & $6.5 \%$ & & \\
\hline Type 2 & 45 & $95.7 \%$ & 43 & $93.5 \%$ & & \\
\hline Duration of Diabetes (yrs) & 12.09 & $(8.61)$ & 10.62 & $(8.82)$ & 0.03 & $0.030^{\neq}$ \\
\hline Treatment mode & & & & & 1.03 & \\
\hline $\mathrm{OAM}^{\S}$ & 24 & $51.1 \%$ & 23 & $50.0 \%$ & & \\
\hline Insulin & 6 & $12.8 \%$ & 8 & $17.4 \%$ & & \\
\hline $\mathrm{OAM}^{\S}$ and insulin & 17 & $36.1 \%$ & 15 & $32.6 \%$ & & \\
\hline HbA1c (\%) & 9.84 & $(1.75)$ & 9.6 & $(1.78)$ & -0.81 & $0.31^{\neq}$ \\
\hline BMI§ $\left(\mathrm{kg} / \mathbf{m}^{2}\right)$ & 28 & $(5.41)$ & 28 & $(5.79)$ & 0.55 & $0.64^{\neq}$ \\
\hline Male & 27 & $(4.05)$ & 27 & $(5.70)$ & 1.02 & $0.14^{\neq}$ \\
\hline Female & 29 & $(6.03)$ & 29 & $(5.79)$ & 1.07 & $0.18^{\neq}$ \\
\hline Waist circumtances (cm) & 94 & $(10.01)$ & 95 & (12.44) & 0.65 & $0.78^{\neq}$ \\
\hline Male & 95 & $(10.01)$ & 97 & $(12.80)$ & 1.68 & $0.35^{\neq}$ \\
\hline Female & 93 & $(11.00)$ & 94 & $(12.18)$ & 0.86 & $0.48^{\neq}$ \\
\hline \multicolumn{7}{|l|}{ C. Psychosocial Social status } \\
\hline Living with family & & & & & 1.59 & $0.49^{\ddagger}$ \\
\hline members & 45 & $95.7 \%$ & 43 & $93.5 \%$ & & \\
\hline Living with friends & 0 & $0 \%$ & 1 & $2.2 \%$ & & \\
\hline Living alone & 2 & $4.3 \%$ & 2 & $4.3 \%$ & & \\
\hline Occupation & & & & & 2.13 & $0.76^{\ddagger}$ \\
\hline Office & 6 & $12.8 \%$ & 5 & $10.9 \%$ & & \\
\hline Factory & 18 & $38.3 \%$ & 14 & $30.4 \%$ & & \\
\hline Fieldwork & 3 & $6.4 \%$ & 5 & $10.9 \%$ & & \\
\hline Housewife & 12 & $25.5 \%$ & 10 & $21.7 \%$ & & \\
\hline Proffesional & 1 & $2.1 \%$ & 4 & $8.7 \%$ & & \\
\hline Retired & 7 & $14.9 \%$ & 8 & $17.4 \%$ & & \\
\hline
\end{tabular}

${ }^{\neq}$analysis by t-test; ${ }^{\ddagger}$ analysis by Chi-square; ${ }^{\S}$ OAM means oral anti-hyperglycaemic medication BMI means body mass index. 
when compared to those with history of hypoglycaemic episodes [M82.45, $\mathrm{SD}=18.48 ; \mathrm{t}(76)=1.65, \mathrm{p}=0.10]$. The finding was not statistically significant.

\subsubsection{Demographic Factors}

After the education intervention subjects $>60$ years old (mean adherence rate $88 \% \pm 15.6$ ) adhered the most to their medication intake. Subjects younger than 40 years old adhered the last to medication intake (mean adherence rate $\left.83 \% \pm 21.9, X^{2}=2.22, \mathrm{df}=2, \mathrm{p}=0.04\right)$. Postknowledge assessment, other demographic data self-care practices were not related to medication adherent practices $(\mathrm{p} \geq 0.05)$.

\subsection{Medication Self-Care and Hb1Ac Levels Wrong Timing of Medication Intake}

Of the 47 subjects from the intervention group who reported adherent to their daily medication intake after the education intervention, 51 subjects $(31.9 \%)$ reported taking their medication at the wrong time. The recommended times for oral anti-hyperglycemic medication (OAM) are: sulphonylureas 30 minutes before food, acarbose with food, metformin with or within 30 minutes after food [33-35]. Short acting and premix insulin are injected at 30 to 45 minutes before food [36]. Subject who took their medication at times other than the above were classified as taking their medication at the wrong time. To assess the effect of wrong medication timing on HbA1c level, unpaired t-test was used. There was a significant difference in $\mathrm{HbAlc}$ results between subjects from the intervention group who took their medication at the correct time $(\mathrm{M}=8.29, \mathrm{SD}=1.39)$ when compared to those who did not $(\mathrm{M}=9.94, \mathrm{SD}=2.18$; t926.18), $\mathrm{df}$ $=-0.32, \mathrm{p}=0.003)$. A similar finding was observed when analysis of wrong time of medication in relationship to HbA1c was done for the whole study group. Subjects who took their medication at the correct time $(\mathrm{M}=8.74, \mathrm{SD}=1.74)$ compared to those who didn't ( $\mathrm{M}$ $=10.00, \mathrm{SD}=2.17 ; \mathrm{t}(71.38), \mathrm{df}=-3.49, \mathrm{p}=0.001)$.

Subjects who took medication at the wrong time were most frequently found to be those who had never attended formal school (mean rank $=91$ ) and least likely those who had tertiary education (mean rank $=$ rank52; $X^{2}=3.38, \mathrm{df}=4, \mathrm{p}=0.41$ ). These findings were not statistically significant.

\subsection{Self-Monitoring of Blood Glucose Self-Care (SMBG)}

\subsubsection{Between Groups}

During follow-up there was a statistically significant difference in SMBG practices between the intervention group $(\mathrm{M}=2.94, \mathrm{SD}=2.25)$ and control group $[\mathrm{M}=$ $0.47, \mathrm{SD}=1.36 ; \mathrm{t}(127.64)=-8.23, \mathrm{p} \leq 0.001]$ with mod- erate effect size (eta squared $=0.06$ ).

\subsubsection{Within Groups}

Within the intervention group, not all the subjects monitored their SMBG four times a week as instructed. During the 24 weeks the mean number of times this was done was $2.94(\mathrm{SD}=2.25)$ ranging between $0-8$ test per week. Despite the inconsistent practices, there was a statistically significant difference in SMBG practices from baseline $(\mathrm{M}=0.60, \mathrm{SD}=1.39)$ to follow-up [M2.94, $\mathrm{SD}$ $=2.25, \mathrm{t} 977)=-8.73, \mathrm{p} \leq 0.001]$ with large effect size (eta squared $=0.32$ ). In addition, there was a significant relationship between total number of SMBG performed and $\mathrm{HbAlc}$ result $(\mathrm{r}=-0.25, \mathrm{p}=0.03)$, carbohydrate intake $(\mathrm{r}=-0.24, \mathrm{p}=0.04)$ and medication adherence practices $(r=+0.27, p=0.03)$. There was no relationship between SMBG practices with demographic data or post-knowledge assessment or level of physical activity.

As for the control group, there was no significant difference in SMBG practices from baseline $(\mathrm{M}=0.70$, $\mathrm{SD}=1.35)$ to follow-up $[\mathrm{M}=0.47, \mathrm{SD}=1.36, \mathrm{t}(72)=$ $0.97, \mathrm{p}=0.34]$ and no relationship was found between the number of blood glucose tests done with demographic or clinical variables.

\section{DISCUSSION}

Concomitant with the increasing global prevalence of diabetes is the increase in medical costs for this population $[48,49]$. One explanation for the heavy economic burden is that a substantial proportion of the cost of diabetes treatment is spent on treating complications [50,51]. Individuals with diabetes who had not received diabetes education had four times more risk of experiencing chronic diabetes complications due to inappropriate selfcare, leading to persistent hyperglycaemic and metabolic perturbations. Hence diabetes self-management education is a critical element of diabetes management.

Despite the high prevalence of poor diabetes control leading to chronic diabetes complications in Malaysia with diabetes, [52-54] most previous studies done in Malaysia have focused on clinical management of the disease and few studies were found on self-care practices and education. Thus this study aimed to examine the effectiveness of a self-efficacy education program to enhance self-care practices and improve glycaemic control of Malaysians with poorly controlled diabetes.

\subsection{Major Findings and Their Significance in Clinical Practices}

This study showed that a brief diabetes education program incorporating self-efficacy principles had different effects in self-care practices and glycaemic control. 


\subsubsection{Comparison between Groups}

The intervention group showed a statistically improvement in $\mathrm{HbAlc}$ levels, self-monitoring blood glucose (SMBG) practices when compared to the control group. Even though not statistically significant, the intervention group has also improved medication self-care practices.

\subsubsection{Analysis within Groups}

At follow-up, within the intervention group, there was a statistically significant improvement in $\mathrm{HbAlc}$ level, SMBG practices and medication self-care. The control group had small improvement in HbA1c levels but none of the self-care practices.

\subsubsection{Effects of Diabetes Education}

Diabetes education intervention was shown to enhanced SMBG and medication adherence practices. Likewise medication adherence and SMBG practices predicted the HbA1c levels at follow-up. The total education time rather than the number of intervention was associated with the above positive outcomes.

Each of the hypothesis is addressed individually before discussing the effect of diabetes education on selfcare practices and glycaemic control.

\subsection{Self-Care Practices}

\subsubsection{Medication Self-Care}

Ho1: There will be no difference in medication adherence self-care practices between adults with poorly controlled diabetes who receive a structured self-efficacy education compared to those who received standard education.

The findings appeared to support the null hypothesis with no difference between the intervention and control groups. However, within the intervention group there was significant improvement from baseline to week 24 . Hence this finding should be interpreted with caution for reasons given below.

One possible reason for the low medication adherence rate $(89.5 \%)$ of the intervention group at end of study was the hypoglycaemia episodes experienced by $14 \%$ of the subjects in this study. Unlike previous studies the cause of hypoglycaemia in the intervention groups was not due to increased insulin dosage because the proposed intervention did not include insulin adjustment $[55,56]$. The hypoglycaemia episodes were most probably caused by better medication adherent practice, reduction of carbohydrate intake and increased physical activity. These subjects self-reported having to reduce their insulin dosage to prevent further hypoglycaemic episodes. By doing so the mean medication adherent rate of these subjects fell to $82 \%$. Medication adherence in this study was de- fined as adherent to $90 \%$ and more of the prescribed medication. To address the possibility of pseudo-medication non-adherence, another sub-analysis was done on the subjects who did not experience hypoglycaemia from the intervention group. Their medication adherence rate was $91 \%$.

Although adherent in medication intake, $37 \%$ of the intervention subjects took their medication (both OAM and insulin) at the wrong time such as more than an hour before or after food intake which had resulted in higher $\mathrm{HbA1c}$ as compared to those who took it at correct timing $(\mathrm{p}=0.003)$. Browne $(2000)$ reported $38 \%$ of Type 2 diabetes subjects $(n=261)$ took their OAM incorrectly in relation to food. However, no assessment was done in that study to identify any relationship between wrong timing of OAM with overall glycaemic control [57]. In this study all subjects were prescribed with conventional insulin like Actrapid or Premix 30/70. Previous studies found that most insulin-treated diabetes patients regardless of the type of diabetes did not follow the recommended pre-meal injection time for conventional insulin injection but administered it at an interval shorter than advised [58-60]. This could have resulted in sufficient time to raise serum levels to correspond with the effect of meals which could contribute to post-prandial hyperglycaemia and higher HbA1c levels [58-60]. No research was found on timing of OAM intake of more than an hour before or after meal in relation to glycaemic control. More importantly, future research needs to explore the underlying reasons of this behavior as it could result not only in post-prandial hyperglycaemia but also hypoglycaemia that could endanger life $[61,62]$. One possible explanation is the subjects lack knowledge about the action mechanism of their prescribed medications. This assumption was supported by the findings that subjects who took their medication at the wrong time were those with less education. Previous studies have shown similar findings $[57,63,64]$. Another possibility was that wrong advice could have been provided by the healthcare professionals. Findings from previous studies reported that only $30 \%-42 \%$ of their subjects who were healthcare professionals that included doctors, nurses and pharmacists were knowledgeable on the action mechanism of OAM [57,63-66].

The detailed investigation of the subjects medication intake behavior in relation to medication adherence selfcare was indeed the strength of this study. The inquiries had shown that presence of hypoglycaemia could contribute to medication non-adherence practice and wrong timing of medication could lead to poor glycaemic control. Previous studies have commented on the paucity of information regarding such topics. Hence this observation requires futher investigation to confirm the cause and effect. 
Existing literature made controversial findings regarding medication compliance and older people. In this study, older subjects were more compliant with medication intake. There are two possible explanations for this finding. First, it was possible that older people were more likely to experience progression of their disease leading to increased awareness of the illness and better motivation to comply with treatment. Second, older people in Malaysia often stay with their families and thus could have received support in medication intake from family members or caretakers. Similar findings were observed in the first study of this portfolio and previous literature [67-69].

\subsubsection{Self-Monitoring Blood Glucose Practices}

Ho2: There will be no difference in SMBG self-care practices between adults with poorly controlled diabetes who receive a structured self-efficacy education compared to those who receive standard education.

There was a significant difference between the intervention and control group SMBG practices and therefore the null hypothesis was rejected. The improvement in SMBG self-care in the intervention group was anticipated not only because of the education intervention, but also because the subjects were provided with free test strips. Due to limited supply of free test strips, the advised frequency of monitoring was not based on the current recommendation of 2 - 3 times per day for insulin users and minimum once a day for those with OAM [70]. Despite the free supply of blood glucose test strips, there was substantial variation between 0-8 times of monitoring per week with a mean of $2.94(\mathrm{SD}=2.25)$ times per week. Since cost was not a barrier for SMBG among the Intervention subjects, infrequent occurred for other reasons. Previous studies had cited these being: attitude toward SMBG, lifestyle interference, inconvenience, pain, old age and cost [70-73]. These barriers were not investigated in this study and should be explored in the future. Thus this finding only partially supported the assumption of this study that people with diabetes when provided with the opportunity to practice SMBG would improve their self-care practices.

The lack of change in the SMBG practices in the control group mirrored results from the first study of this portfolio [67]. As explained earlier, Malaysian engage in social medicine where the government heavily subsides the cost of medication for patients attending government-run healthcare facilities [74]. The government, however does not finance the cost of SMBG. This could act as a financial to SMBG self-care especially for patients from lower socio-economic backgrounds.

Earlier researcher has reported conflicting findings on the efficacy of SMBG among Type 2 diabetic subjects, especially those prescribed with OAM [75-77]. In this study the intervention group comprised $95 \%$ of Type 2 diabetic of which $78 \%$ were prescribed on OAM and combination therapy. These subjects had lower HbAlc levels compared to the control group. This could be due to more frequent SMBG practices enhancing intervention subject's medication adherence. In addition, there was also a significant relationship between total number SMBG performed and $\mathrm{HbAlc}$ result $(\mathrm{p}=0.03)$ and carbohydrate intake $(p=0.04)$. The findings of this study are consistent with previous research reporting a negative correlation between frequency of SMBG with HbAlc levels [78,79]. The increased frequency of SMBG had enhanced the self-care practices of the intervention group in dietary and medication intake.

Previous study found improved $\mathrm{Hb} 1 \mathrm{Ac}$ levels with self-adjusted of insulin dosage [79]. However, in this study, increases in medication dosage by the attending doctors did not lower the HbAlc of the intervention group $(p=0.57)$. Instead the intervention subjects were shown on meal-related SMBG to identify excessive carbohydrate intake. It was explained to the subjects that the same meal, if there was a difference between the premeal and the 2-hour post-meal blood glucose levels greater than $4 \mathrm{mmol} / \mathrm{L}$, it might indicate excessive carbohydrate intake for that particular meal. For example, if the pre-meal blood glucose was $8 \mathrm{mmol} / \mathrm{L}$ and 2 hour later, the blood glucose level was $16 \mathrm{mmol} / \mathrm{L}$, there could be due to excessive carbohydrate intake for that particular meal. However, if the pre-meal blood glucose was 14 $\mathrm{mmol} / \mathrm{L}$ and 2 hours later, the blood glucose level was 16 $\mathrm{mmol} / \mathrm{L}$, the post-prandial hyperglycaemia might not be due to intake of food but other causes. To increase their self-efficacy in dietary management, they were then guided to identify the carbohydrate food items in the meal so as to reduce the carbohydrate intake in the future. At the end of this study, subjects who practiced more frequent meal related SMBG reduced their carbohydrate intake $(p=0.04)$. Similar findings have been reported in previous studies [80,81]. Furthermore, it was also explained that persistent fasting hyperglycaemia might be due to medication non-adherence and wrong timing of medication intake. With self-efficacy education the intervention group improved its medication intake practices $(p=0.03)$. The above findings had supported the assumption of this study which argued the beneficial effects of SMBG with treatment modifications.

\subsubsection{Glycated Haemoglobin}

Ho3: There will be no difference in glycaemic control measured by glycated haemoglobin (HbA1c) between adults with poorly controlled diabetes who received a structured self-efficacy education compared to those who receive standard education.

Compared to the control group, the intervention group 
significantly improved its $\mathrm{HbAlc}$ levels with a reduction of $1.1 \%$ compared to baseline which means the null hypothesis was rejected. This is an important finding as previous clinic trials have reported that reduction of $\mathrm{HbA} 1 \mathrm{c}$ by $1 \%$ is associated with reduction of diabetes complications by $21 \%$ [82]. The proposed intervention of this study was an education program with no change of medication by the investigator. Although the medication prescriptions of some subjects were increased by the attending doctors during the course of study, this has no significant effect on the HbAlc levels of the subjects at the end of the study $(p=0.57)$. Hence it could argued that improvement in $\mathrm{HbAlc}$ was due to the education intervention enhancing self-care practices in SMBG $(p=$ $0.001)$, medication adherence $(\mathrm{p}=0.04)$, physical activities $9 p=0.002)$ and dietary intakes. These are the cornerstone of diabetes management. Previous researchers have reported similar findings [83-87]. However, whether the improved self-care practices were due to subject's improved self-efficacy could not be ascertained as no assessment of self-efficacy was done before and after the intervention.

Not all subjects in the intervention group lowered their $\mathrm{HbA} 1 \mathrm{c}$. The glycaemic control of $20 \%$ of the intervention subjects deteriorated despite education. This could be due to several reasons. During the data collection process, it was observed that $23 \%$ of intervention subject who were older, female and with less education had problem attending education session due to lack of transport thus they received less education $(p=0.006)$. Subjects with transportation problem had statistically higher HbAlc at follow-up $(p=0.03)$. Although the barriers to transportation were not assessed in this study, previous studies found that distance from health facilities was positively correlated to glycaemic control of the subject $[88,89]$. Other studies have revealed the importance of social support to subject's glycaemic control [90-92]. In view of the increasing incidence of diabetes in Malaysia, social support warrants future research as this may be a barrier to subjects attaining glycaemic control.

Another barrier to education observed in this study was telephone access. Over the last decades in Malaysia, mobile phone have gained in popularity at the expense of landlines. This study was found that although mobile phones were readily available within a family, they were usually used by younger members of the family or the male subjects who were employed. As two-third of the subjects were older women or housewives, they were liable to have problems with phone access during the day. It was observed that subjects with less financial resources were likely to purchase low cost prepaid phone cards (RM 5 or RM 10). This could have contributed to the frequent change of phone numbers which further contributed to telephone access problems. Three previous studies done in Malaysia had used a phone intervention for survey and appointment reminder purposes rather than education [93-95]. Although these studies did not report problems with phone access, one study reported only a $67 \%$ success rate. Ten percent of the potential subjects in another study did not have a mobile phone call were answered by caregivers rather than the patients themselves. In addition, the mean age for two of the above three studies was 38.2 years.

Not all subjects in the control group experienced deterioration in their glycaemic control. Some control subjects improved their HbAlc at the end of this study. As discussed earlier, the increased in medication prescribed by the attending doctors did not lower their HbAlc levels $(p=0.57)$. There was also no significant change in the self-care practices among control subjects. Hence the silent question is what could have contributed to improved glycaemic control among the control group without the effect of additional medication or enhanced self-care like as in the intervention group. Previous researchers had reported recruitment to a clinical trial itself improves glycaemic control in patients with diabetes [96]. Another possible reason could be the use of complementary therapy. Previous studies done in Malaysia reported the popular use of the complementary therapy [97-99]. Some complementary therapies may contain anti-diabetis effects $[100,101]$. This could result in over-medication if the subjects also consumed the doctor's prescription at the same time without informing their attending doctors. Due to limitations of this study, use of complementary medication by both the study groups was not investigated.

The higher frequency of SMBG performed by the intervention group compared to the control group could have influenced the HbAlc improvement as SMBG results provided real time effects of self-care practices./ Subjects in this study improved their medication adherence rate $(p=0.03)$ in within group comparison and reduced carbohydrate intake $(p=0.04)$ based on their SMBG practice results. The results of previous studies supported these findings [102-104].

\section{CONCLUSION}

This research has shown a brief structured education program that incorporated behavior science specifically self-efficacy was effective in enhancing self-care practices (SMBG and medication adherence) and improving glycaemic control in the intervention group. The brief education implemented in this study appeared to enhance self-efficacy in self-care practices leading to behavioral change and better clinical outcomes.

\section{Practice Implications}

The results of this study have implications for patient 
education, clinical practice and policy-making.

Subjects who were elderly and with less education in this study did not gain the same benefits from the intervention compared to the younger subjects with more education. This suggests the importance of an individualized approach. When educating the elderly and those with less education, sessions may need to be longer and approaches specifically designed to achieve maximum benefit.

It is usual practice in the study settings that more subjects with Type 1 diabetes and on insulin treatment rather than Type 2 diabetes on OAM are referred for diabetes education. In this study, the difference of knowledge scores between Type 1 and Type 2 subjects in the intervention group had changed from significant at baseline to non-significant after the intervention which suggested that education could benefit all hence everyone diabetes in Malaysia regardless of type of diabetes or treatment mode should be provided with education to enhance their knowledge and self-care management.

In this study despite good overall adherence to medication intake, wrong timing of medication intake in relation to meal-intake was observed to decrease glycaemic control. During the education sessions, medication intake in relation to meal-timing should be emphasized as well as encouraging medication adherence.

With less than 500 registered dieticians in Malaysia, there is a considerable shortage of dietary services provided by dieticians. Since diabetes nurse educators provide most of the teaching for people with diabetes, they are in unique position to assist dieticians in enhancing dietary knowledge and self-care. This could be done by emphasizing meal-related SMBG practices in dietary management and problem solving skills which are an important aspect of diabetes self-care.

In this study, by providing the required resources (blood glucose strip and knowledge) to the interventions subjects, the majority of them regardless of demographic differences were willing to practice SMBG. In addition, the frequency of SMBG in this study was found to correlate with significant clinical improvement and better self-care practices. All individuals with diabetes regardless of treatment mode and age group should be encouraged to practice SMBG.

\section{REFERENCES}

[1] Ponte C. (1996) Non-insulin-dependent diabetes mellitus -Current practice and future trends. Journal of the American Pharmaceutical Association (Washington DC: 1996), 36, 50-58.

[2] Mensing, C., Boucher, J., Cypress, M., Weinger, K., Mulcaby, K., Barta, P., et al. (2000) National standards for diabetes self-management education. Diabetes Care, 23,
682-689. doi:10.2337/diacare.23.5.682

[3] Bailey, C. and Turner, R. (1996) Metformin. The New England Journal of Medicine, 334, 574-579.

[4] Parving, H., Brochner-Mortensen, J., Goniis, R., Anderson, S. and Amer, P., Irbesartan in Patients with Type 2 Diabetes and Microalbuminuria Study Group (2001) The effect of Irbesartan on the development of diabetic nephropathy in patients with type 2 diabetes. The New England Journal of Medicine, 345, 870-878. doi:10.1056/NEJMoa011489

[5] Foreyt, J. and Poston, W.P. (1999) The challenge of diet, exercise and lifestyle modification in the management of the obese diabetic patient. International Journal of Obesity, 23, S5-S11.

[6] Baliga, B. and Fonseca, V. (1997) Recent advances in the treatment of type II diabetes mellitus. American Family Physician, 55, 817-824.

[7] Mann, J. (2000) Should the results of the HOPE study affect nephrological practice? For the HOPE investigators. Nephrology Dialysis Transplantation, 15, 453-454. doi:10.1093/ndt/15.4.453

[8] Stang, M., Wysowski, D.K. and Butler-Jones, D. (1999) Incidence of lactic acidosis in metformin users. Diabetes Care, 22, 925-957. doi:10.2337/diacare.22.6.925

[9] Anonymous (2003) Schedule of pharmaceutical benefits. Department of Health and Ageing, Canberra. www.hic.gov.au

[10] Whittemore, R. (2000) Strategies to facilitate lifestyle change associated with diabetes mellitus. Journal of Nursing Scholarship, 32, 225-232. doi:10.1111/j.1547-5069.2000.00225.x

[11] Foreyt, J. and Poston, W.P. (1999) The challenge of diet, exercise and lifestyle modification in the management of the obese diabetic patient. International Journal of Obesity, 23, S5-S11.

[12] Wing, R.R. and Anglin, K. (1996) Effectiveness of a behavioural weight control program for blacks and whites with NIDDM. Diabetes Care, 19, 409-413. doi:10.2337/diacare.19.5.409

[13] Nath C. and Ponte C.D.., (2001) Managing insulin therapy. Nursing Management, 32, 38-40.

[14] Mensing, C., Boucher, Cypress, M., Weinger, K., Mulcaby, K., Barta, P., et al. (2000) National standards for diabetes self-management education. Diabetes Care, 23, 682-689. doi:10.2337/diacare.23.5.682

[15] DeFronzo, R.A. (1999) Pharmacologic therapy for type 2 diabetes mellitus. Annals of Internal Medicine, 131, 281303.

[16] Wen, L., Shepherd, M. and Parchaman, M. (2004) Family support, diet and exercise among older Mexican Americans with type 2 diabetes. The Diabetes Educator, 30, 980-993. doi: $10.1177 / 014572170403000619$

[17] Savoca, M., Miller, C. and Quandt, S. (2004) Profiles of people with type 2 diabetes mellitus. The extremes of glycaemic control. Social Science and Medicine, 58, 26552666. doi:10.1016/j.socscimed.2003.09.031

[18] Turner, R., Cull, C. and Holman, R. (1996) United King- 
dom Prospective Diabetes Study 17: A 9-year update of a randomized, controlled trial on the effect of improved metabolic control on complications in non-insulin dependent diabetes mellitus. Annals of Internal Medicine, 124, 136-145.

[19] Arc, A., Korhonen, T. and Halinen, M. (1978) Phenformin-induced lactic acidosis precipitated by tetracycline. Lancet, 1, 673-674.

[20] Somogyl, A., Stockley, C., Keal, J., Rolan, P. and Bockner, F. (1987) Reduction of metformin renal tubular secretion by cimetidine in man. British Journal of Pharmacology, 23, 545-551.

[21] Lubbos, H., Miller, J. and Rose, L.I. (1995) Oral hypoglycemic agents in type II diabetes mellitus. American Family Physician, 52, 2075-2078.

[22] Yeap, B.B. (2001) Primary care diabetes: What options are there. Australian Family Physician, 30, 1122-1127.

[23] Kubacka, R., Antal, E., Juhi, R. and Weishman, L. (1996) Effects of aspirin and ibuprofen on the pharmacokinetics and pharmacodynamics of glyburide in healthy subjects. The Annals of Pharmacotherapy, 221, 20-26.

[24] Hansen, J. and Kristensen, M. (1991) Suiphaphenazoleinduced hypoglycaemic attacks in tolbutamide-treated diabetics. Lancet, 2, 1298-1301.

[25] Kivisto, K. and Neuvonen, P. (1991) Effect of magnesium hydroxide on the absorption and efficacy of tolbutamide and chiorpropamide. European Journal of Clinical Pharmacology, 42, 675-680.

[26] Ben-Ami, H., Nagachandran, P., Mendelson, M. and Edoute, Y. (1999) Drug-induced hypoglycemic coma in 102 diabetic patients. Archives of Internal Medicine, 159, 281-284.

[27] Nelson, K., Reiber, G. and Boyko, E. (2002) Diet and exercise among adults with type 2 diabetes: Findings from the third national health and nutritional examination survey (NHANES III). Diabetes Care, 25, 1722-1728. doi:10.2337/diacare.25.10.1722

[28] Huang, C.-L., Wu, S.-C., Jeng, C.-Y. and Lin, L.-C. (2004) The efficacy of a home-based nursing program in diabetic control of elderly people with diabetes mellitus living alone. Public Health Nursing, 2, 49-56. doi:10.1111/j.1525-1446.2004.21107.x

[29] Hurley, C.C. and Shea, C.A. (1992) Self-efficacy: Strategy for enhancing diabetes self-care. The Diabetes Educator, 18, 146-150. doi:10.1177/014572179201800208

[30] Aljasem, L.I., Peyrot, M., Wissow, L. and Rubin, R.R. (2001) The impact of barriers and self-efficacy on self care behaviors in type 2 diabetes. The Diabetes Educator, 27, 393-404. doi:10.1177/014572170102700309

[31] Burns, N. and Grove, S.K. (2001) The practice of nursing research-conduct, critique \& utilization. W.B. Saunders Company, Philadelphia.

[32] William, K. and Bond, M. (2002) The role of self-efficacy, courage, outcome expectance and social support in selfcare behaviors of diabetes. Psychology, Health and Medicine, 7, 127-141. doi:10.1080/13548500120116076

[33] UK Prospective Diabetes Study Group (1998) Tight blood pressure control and risk of macrovascular and mi- crovascular complications in type 2 diabetes: UKPDS 38 . British Medical Journal, 317, 703-713. doi:10.1136/bmj.317.7160.703

[34] Diabetes Control and Complications Trial Research Group (1993) The effect of intensive treatment of diabetes on the development and progression of long-term complications in insulin-dependent diabetes mellitus. The New England Journal of Medicine, 329, 977-986. doi:10.1056/NEJM199309303291401

[35] Ohkubo, Y., Kishikawa, H., Araki, E., Myata, T., Isamu, S., Motoyoshi, S., et al. (1995) Intensive insulin therapy prevents the progression of diabetic microvascular complications in Japanese patients with type 2 diabetes mellitus: A randomized prospective 6-year study. Diabetes Research and Clinical Practice, 28, 103-117. doi:10.1016/0168-8227(95)01064-K

[36] Swift, C., Armstrong, J., Berman, K., Cambell, R. and Pond-Smith, D. (1995) Attitudes and beliefs about exercise among persons with non-insulin dependent diabetes. The Diabetes Educator, 21, 523-540. doi: $10.1177 / 014572179502100607$

[37] Polit, D.F. and Hungler, B.P. (2004) Nursing researchprinciple and methods Lippincott Williams \& Wilkins, Philadelphia.

[38] Ponnusankar, S., Surulivelrajan, M., Nunjundiah, A. and Suresh, B. (2004) Assessment of impact of medication counseling on patients' medication knowledge and compliance in an outpatient clinic in South India. Patient Education and Counseling, 54, 55-60. doi:10.1016/S0738-3991(03)00193-9

[39] Bergenstal, R.M. and Gavin, J.R. (2005) Global Consensus conference on Glucose monitoring panel. The role of self monitoring of blood glucose in the care of people with diabetes: Report of global consensus conference. The American Journal of Medicine, 118, 15-65.

[40] Renard, R. (2005) Monitoring glycaemic control: The importance of self-monitoring of blood glucose. The American Journal of Medicine, 118, 12S-19S. doi:10.1016/j.amjmed.2005.07.052

[41] Tan, M.Y. and Magarey, J. (2008) Self-care practices of Malaysian adults with diabetes and sub-optimal glycaemic control. Patient Education and Counseling, 72, 252267. doi:10.1016/j.pec.2008.03.017

[42] Mastura, I., Mimi, O., Piterman, L., Teng, C.L. and Wijesinha, S. (2007) Self-monitoring of blood glucose among diabetes patients attending government health clinics. Medical Journal of Malaysia, 62, 147-151.

[43] Bonora, R., Targher, G., Formentini, G., Calcaterra, F., Lombard, S., Marini, F., et al. (2003) The Metabolic syndrome is an independent predictor of cardiovascular disease in type 2 diabetic subjects. Prospective data from the Verona diabetes complications study. Diabetes Medicine, 21, 52-58. doi:10.1046/j.1464-5491.2003.01068.x

[44] Burno, G., Merletti, F., Biggeri, A., Bargero, G., Ferrero, S., Runzo, C., et al. (2004) Metablic Syndrome as a predictor of all-cause and cardiovascular mortality in type 2 diabetes: The casale Monferrato study (metabolic syndrome/insulin resistance syndrome/Pre-diabetes). Diabetes Care, 27, 2689-2694. doi:10.2337/diacare.27.11.2689 
[45] Reddy, H.T., Gopinath, A., Morrissey, J. and Patel, V. (2007) Identification of metabolic syndrome in type 1 and 2 diabetes patients and its role in clinical practices. Diabetes, 56, A-589.

[46] Santos, J.R.A. (1999) Cronbach's Alpha: A tool for assessing the reliability of scales. Extension Journal, 37, 1-6.

[47] Kuo, Y., Raji, M., Markides, K., Ray, L., Espino, D. and Godwin, J. (2003) Inconsistent use of diabetes medications, diabetes complications and mortality in older Mexican Americans over a 7-year period. Diabetes care, 26, 3054-3060. doi:10.2337/diacare.26.11.3054

[48] Currie, C.J., Morgan, C.L., Dixon, S., McEwan, P., Marchant, N., Bearne, A., et al. (2004) Comparative estimates of the financial burden to the UK health system of hospital care for people with and without diabetes in the year before death. Diabetes Research and Clinical Practice, 65, 267-274. doi:10.1016/j.diabres.2004.01.009

[49] American Diabetes Association (2008) Economic costs of diabetes in the US, 2007. Diabetes Care, 31, 596-615.

[50] Brown, J., Pedual, K. and Bakst, A. (1999) The progresssion cost of complications in type 2 diabetes mellitus. Archives of Internal Medicine, 159, 1873-1880. doi:10.1001/archinte.159.16.1873

[51] Extarro, L., Songer, T., Zhang, P. and Engelgau, M. (2004) The economic burden of diabetes. PharmacoEconomics, 22, 149-164.

[52] Yusof, M.I., Sulaiman, A.R. and Muslim, D.A.J. (2007) Diabetic foot complications a two-year review of limb amputation in a Kelantanese population. Singapore Medical Journal, 48, 729-732.

[53] Mafauzy, M. (2006) Diabetes control and complications in public hospitals in Malaysia. Medical Journal of Malaysia, 4, 477-483.

[54] Ismail, I.S., Wan Nazimoon, W.M., Wan Mohamad, W.B., Letchuman, R., Singaraveloo, M., Pendek, R., et al. (2000) Sociodemographic determinants of glycaemic control in young diabetic patients in peninsular Malaysia. Diabetes Research and Clinical Practice, 47, 57-69. doi:10.1016/S0168-8227(99)00104-7

[55] Diabetes Control and Complication Trial Research Group (1993) The effect of intensive treatment of diabetes on the development and progression of long-term complications in insulin-dependent diabetes mellitus. New England Journal of Medicine, 329, 977-986. doi:10.1056/NEJM199309303291401

[56] Alonso, D.S. (2004) Hypoglycaemia as a barrier to glycaemic control. Diabetes Complications, 18, 60-68. doi:10.1016/S1056-8727(03)00058-8

[57] Brown, D., Avery, L., Turner, B., Kerr, D. and Cavan, D. (2000) What do patients with diabetes know about their tablets? Diabetic Medicine, 17, 528-531. doi:10.1046/j.1464-5491.2000.00327.x

[58] Kinmonth, A. (1980) Timing of pre-breakfast insulin injection and postprandial metabolic control in diabetic children. British Medical Journal, 280, 604-606. doi:10.1136/bmj.280.6214.604

[59] Ahmad, A.B.E., Badgandi, M. and Home, P.D. (2001)
Interval between insulin injection and meal in relation to glycated haemoglobin. Practical Diabetes International, 18, 51-56. doi: 10.1002/pdi.126

[60] Cohen, L.S., Sedhom, L., Salifu, M. and Friedman, E.A. (2007) Inpatient diabetes management: Examining morning practice in an acute care setting. The Diabetes Educator, 33, 483-492. doi:10.1177/0145721707301351

[61] Bruce, D.G., Chisholm, D., Storlien, L. and Kragen, F. (1985) Physiological importance of deficiency in early prandial insulin secretion in non-insulin-dependent diabetes. Diabetes, 37, 736-744.

doi:10.2337/diabetes.37.6.736

[62] Cryer, P.E., Davis, S.N. and Shamoon, H. (2003) Hypoglycaemia in Diabetes. Diabetes Care, 26, 1902-1912. doi:10.2337/diacare.26.6.1902

[63] Kuo, Y., Raji, M., Markides, K., Ray, L., Espino, D. and Goodwin, J. (2003) Inconsistent use of diabetes medications, diabetes complications and mortality in older Mexican Americans over a 7-year period. Diabetes Care, 26, 3054-3060. doi:10.2337/diacare.26.11.3054

[64] Kripalani, S., Henderson, L.E., Chiu, E.Y., Robertson, R., Kolm, P. and Jacobson, T.A. (2006) Predictors of medication self-management skill in a low-literacy population. Journal of General Internal Medicine, 21, 852-856. doi:10.1111/j.1525-1497.2006.00536.x

[65] Mohd, A.S. (2006) Type 2 diabetes in Malaysia: Perspective of Malay patients and their health care professionals [Thesis (unpublished)]. University of Nottingham, Nottingham.

[66] Uding, A., Jackson, E. and Hart, A. (2002) Efficacy of a teaching intervention on nurses knowledge regarding diabetes. Journal for Nurses in Staff Development, 18, 297-303. doi:10.1097/00124645-200211000-00003

[67] Tan, M.Y. and Magarey, J. (2008) Self-care practices of Malaysian adults with diabetes and sub-optimal glycaemic control. Patient Education and Counseling, 72, 252267. doi:10.1016/j.pec.2008.03.017

[68] Silliman, R.A., Shelah, B.M., Khan, A., Dukes, K.A. and Sullivan, L.M. (1996) The care of older persons with diabetes mellitus: Families and primary care physicians. Journal of the American Geriatrics Society, 44, 13141321.

[69] Lee, V.W.Y. and Leung, P.Y. (2003) Glycemic control and medication compliance in diabetes patients in a pharmacist-managed clinic in Hong Kong. American Journal of health-system Pharmacy, 60, 2593-2596.

[70] Blonde, L. and Karter, A.J. (2005) Current evidence regarding the value of self-monitored blood glucose testing. The American Journal of Medicine, 118, 205-265.

[71] Adam, A., Mah, C., Soumerai, S., Zhang, F., Barton, M. and Ross-Degnam, D. (2003) Barriers to self-monitoring of blood glucose among adults with diabetes in an HMO: A cross sectional study. BMJ Health Services Research, 3, 6-10. doi:10.1186/1472-6963-3-6

[72] Siegel, J. (1991) Barriers to the effective use of capillary blood glucose monitoring in extended care facilities. The Diabetes Educator, 17, 381-383. doi: $10.1177 / 014572179101700510$ 
[73] Vincze, G., Barner, J. and Lopez, D. (2004) Factor associated with adherence to self-monitoring of blood glucose among persons with diabetes. The Diabetes Educator, 30, 112-125. doi:10.1177/014572170403000119

[74] Merican, M.I., Rohaizat, Y. and Haniza, S. (2003) Developing the Malaysian Health System to meet the challenges of the future. Medical Journal of Malaysia, 59, 84-93.

[75] Brown, S. (1992) Meta-analysis of diabetes patient education research: Variations in intervention effects across studies. Research in Nursing and Health, 15, 409-419. doi:10.1002/nur.4770150603

[76] Davidson, M.B., Castellanos, M., Kain, C. and Suran, P. (2005) The effect of self-monitoring of blood glucose concentration on glycated haemoglobin levels in diabetic patients not taking insulin: A blinded randomized trial. American Journal of Medicine, 118, 422-425. doi:10.1016/j.amjmed.2004.12.006

[77] Wen, L., Parchman, M., Linn, W. and Lee, S. (2004) Association between self-monitoring of blood glucose and glycaemic control in patients with type 2 diabetes meelitus. American Journal of Health-System Pharmacy, 61, 2401-2405.

[78] Nyomba, B., Berard, I. and Murphy, L. (2003) Facilitating access to glucometer reagents increase blood glucose self-monitoring frequency and improves glycaemic control: A prospective study in insulin-treated diabetic patients. Diabetic Medicine, 21, 129-135. doi:10.1046/j.1464-5491.2003.01070.x

[79] Monnier, L., Collette, C., Lapinski, H. and Boniface, H. (2004) Self-monitoring of blood glucose in diabetic-patient: From the least common denominator to the greatest common multiple. Diabetes Metabolism, 30, 113-119. doi:10.1016/S1262-3636(07)70097-6

[80] Muchmore, D., Springer, J. and Miiler, M. (1994) Selfmonitoring of blood glucose in overweight type 2 diabetic patients. Acta Diabetologia, 31, 215-219. doi:10.1007/BF00571954

[81] Schwedes, U., Merter, G. and Siebolds, M. (2002) For the SMBG study Group. Meal-related structured self-monitoring of blood glucose-effect on diabetes control in noninsulin-treated type 2 diabetic patients. Diabetes Care, 25, 1928-1932. doi:10.2337/diacare.25.11.1928

[82] United Kingdom Prospective Diabetes Study Group (1998) Intensive blood glucose control with sulphonylurease or insulin compared with conventional treatment and risk of complications in patients with type 2 diabetes. Lancet, 352, 837-853. doi:10.1016/S0140-6736(98)07019-6

[83] Evans, J., Newton, R., Ruta, D., MacDonald, T., Stevenson, R. and Morris, A. (1999) Frequency of blood glucose monitoring in relation to glycaemic control: Observational study with diabetes database. British Medical Journal, 319, 83-86. doi:10.1136/bmj.319.7202.83

[84] Rhee, M.K., Slocum, W., Ziemer, D.C., Culler, S.D., Cook, C.B., El-Kebbi, I.M., et al. (2005) Patient adherence improves glycaemic control. The Diabetes Educator, 31, 240-250. doi:10.1177/0145721705274927

[85] Krass, I., Armour, C., Mitchell, B., Brilliant, M., Dienaar, R., Hughest, J., et al. (2007) The pharmacy Diabetes Care
Program: Assessment of a community pharmacy diabetes service model in Australia. Diabetic Medicine, 24, 677 683. doi:10.1111/j.1464-5491.2007.02143.x

[86] Murata, G., Shah, J., Duckworth, W., Wendel, C., Mohler, M. and Hoffman, R. (2004) Food frequency questionnaire results correlate with metabolic control in insulin treated veterans for with type 2 diabetes: The diabetes outcomes in Veterans Study. Journal of American Dietetic Association, 12, 1816-1826. doi:10.1016/j.jada.2004.09.026

[87] Suppapitiporn, S., Chindavijak, B. and Onsanit, S. (2005) Effects of diabetes drug counseling by the pharmacist, diabetic disease booklet and special medication containers on glycaemic control of type 2 diabetes mellitus: A randomized controlled trial. Journal of the Medical Association of Thailand, 88, S134-S141.

[88] Arcury, T., Preisser, J., Gesler, W. and Powers, J. (2005) Access to transportation and health care utilization in a rural region. Journal of Rural Health, 21, 31-38. doi:10.1111/j.1748-0361.2005.tb00059.x

[89] Strauss K. (2006) Driving distance as a barrier to glycaemic control in diabetes. Journal of general Internal Medicine, 21, 378-380. doi:10.1111/j.1525-1497.2006.00386.x

[90] Wen, L.K., Parchman, M.L. and Shepherd, M.D. (2004) Family support and diet barriers among older Hispanic adults with type 2 diabetes. Family Medicine, 36, 423430.

[91] Gleeson-Kreig, J.M., Bernal, H. and Wooley, S. (2002) The role of social support in the self-management of diabetes mellitus among a Hispanic population. Public Health Nursing, 19, 215-222. doi:10.1046/j.0737-1209.2002.19310.x

[92] Westaway, M.S., Seager, J.R., Rheeder, P. and Van Zyl, D.G. (2005) The effect of social support on health, well being and management of diabetes mellitus: A black South African Perspective. Ethnicity and Health, 10, 7389. doi:10.1080/1355785052000323047

[93] Khoo, K.L., Liew, Y.M., Tan, H., Dsmnhi, J.S. and Hatijah, B.A. (1999) Patient's knowledge and attitude towards treatment and control of hypertension: A nationwide telephone survey conducted in Malaysia. The Medical Journal of Malaysia, 54, 37-46.

[94] Leong, K.C., Chen, W.S., Leong, K.W., Mastura, I., Mimi, O., Sheikh, M.A., et al. (2006) The use of text messaging to improve attendance in primary care: A randomized controlled trial. Family Practice, 23, 699-705. doi:10.1093/fampra/cml044

[95] Zailinawatin, A.H., Ng, C.J. and NIk-Sherina, H. (2006) Why do patients with chronic illness fail to keep their appointments? A telephone interview. Asia Pacific Journal of public Health, 18, 1-2.

[96] Gale, E.A., Beattie, S.D., Hu, J., Koivisto, V. and Tan, M. (2007) Recruitment to a clinical trial improves glycaemic control in patients with diabetes. Diabetes Care, 30, 29892992. doi: $10.2337 / \mathrm{dc} 07-0155$

[97] Hassan, F. and Shaaban, J. (2005) Use of traditional/ complimentary medicine $(\mathrm{T} / \mathrm{CM})$ among adults patients attending family medicine clinic at Hospital University Sains Malaysia. International Medical Journal, 12, 133- 
138.

[98] Ariff, K.M. and Beng, K.S. (2006) Cultural health beliefs in a rural family practice: A Malaysian perspective. Australian Journal of Rural Health, 14, 2-8. doi:10.1111/j.1440-1584.2006.00747.x

[99] Crabtree, S.A. (2005) Medication, healing and resistance in East Malaysia. Mental Health, Religion \& Culture, 8, 17-25. doi:10.1080/13674670410001666552

[100] Shane-McWhorter, L. (2001) Biological complementary therapies: A focus on botanical products in diabetes (From research to practice/complementary \& integrative medicine). Diabetes Spectrum, 14, 199-208. doi:10.2337/diaspect.14.4.199

[101] Dham, S., Shah, V., Hirsch, S. and Banerji, M. (2006) The role of complementary and alternative medicine in diabetes. Current Diabetes Report, 6, 251-258.

doi:10.1007/s11892-006-0042-7
[102] Persell, S.D., Keating, N.L., Landrum, M.B., Landon, B.E., Ayanian, J.Z., Borbas, C., et al. (2004) Relationship of diabetes-specific knowledge to self-management activities, ambulatory preventive care and metabolic outcomes. Preventive Medicine, 39, 746-752.

doi:10.1016/j.ypmed.2004.02.045

[103] LeRoith, D. and Smith, D.O. (2005) Monitoring glycaemic control: The cornerstone of a diabetes care. Clinical Therpeuctics, 27, 1489-1499. doi:10.1016/j.clinthera.2005.10.010

[104] Guerci, B., Drouin, P., Grange, V., Boungneres, P., Fontaine, P., Kerlan, V., et al. (2003) Self-monitoring of blood glucose significantly improve metabolic control in patients with type 2 diabetes mellitus: The Auto-Surveillance Intervention Active (ASIA) study. Diabetes \& $\mathrm{Me}$ tabolism, 29, 587-594.

doi:10.1016/S1262-3636(07)70073-3 